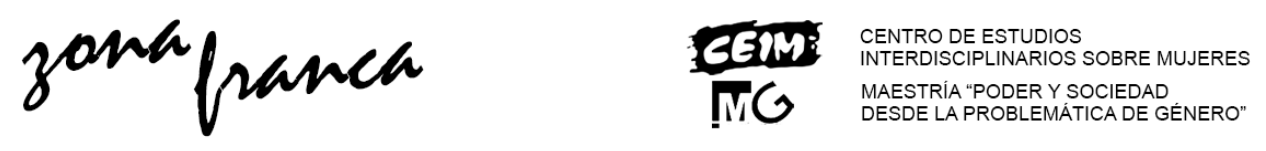

\title{
Cuando lo esencial no es tan invisible a los ojos. Develando las asociaciones entre el género y el idioma inglés.
}

Glenda Marcia Megna

\section{Resumen}

A lo largo de los últimos veinte años innumerables escritoras, historiadoras, antropólogas y docentes impulsadas por los Estudios de Género y la segunda ola del feminismo, que se propagaba gradualmente en América Latina, se han ocupado de develar instancias sexistas plasmadas y naturalizadas en los libros de textos y manuales escolares usados en los distintos niveles del sistema educativo en Argentina. De hecho, es innegable que el análisis de los libros como herramientas pedagógicas de imposición cultual con perspectiva de género marcó un hito en la educación argentina. Sin embargo, dicha investigación no fue reflejada ni muy difundida en los libros de texto para la enseñanza del idioma inglés, debido a que las inequidades de género presentes en los mismos no han sido frecuentemente utilizadas como objeto de estudio. En virtud de ello, el propósito de este artículo apunta a la difusión de mis aportes pedagógicos así como también a la promoción de una educación no sexista que brinde igualdad de oportunidades para los estudiantes, ya que considero que compartiendo nuestras experiencias académicas-pedagógicas con colegas enriquece y propicia una evolución en la educación y en toda la comunidad educativa.

Palabras claves: Los libros de textos como herramientas pedagógicas de imposición cultural - Perspectiva de género - Educación no sexista - Igualdad de oportunidades.

\section{When the essential is not so invisible to the eye. Unveiling the association between English and Gender.}

\section{Abstract}

*Universidad Nacional de Rosario. Contacto: glendamegna@yahoo.com.ar

Glenda Marcia Megna. "Cuando lo esencial no es tan invisible a los ojos. Develando las asociaciones entre el género y el idioma inglés" en Zona Franca. Revista del Centro de estudios Interdisciplinario sobre las Mujeres, y de la Maestría poder y sociedad desde la problemática de Género, N²6, 2018 pp.4-28. ISSN, 2545-6504. Recibido: 1 de junio, 2018;

Aceptado: 27 de agosto 2018

Revista Zona Franca- Centro de estudios interdisciplinario sobre las mujeres (CEIM)- Maestría poder y sociedad desde la problemática de género (MG), Rosario, Argentina. ISSN, 2545-6504 http://zonafranca.unr.edu.ar/index.php/ZonaFranca| Numero 26 (2018). 
Over the last twenty years, myriads of writers, historians, anthropologists and teachers, encouraged by the influence of Gender Studies and the second wave of feminism that was gradually spreading over Latin America, have been engaged to unveil examples of sexism that were lightly illustrate in EFL (English as a foreign language) textbooks used in different educational stages in Argentina. In fact, it is undeniable that the analysis of school textbooks based on gender perspective has marked a turning point in the field of Argentinian education due to the ideological and cultural functionthat books fulfill. Nevertheless, gender research has not been carried out in English textbooks in the same manner due to the fact that the cases of gender inequality depicted have not been frequently considered as an object of study as they had been in Spanish school textbooks. Hence, the purpose of this article is to to eliminate a gender-biased education so as to promote and provide equal opportunities to students and to disseminate my pedagogical contribution since I firmly believe that by sharing our academic and pedagogical experiences with our colleagues enriches and favours a remarkable educational development.

Key words: The ideological and cultural function that books fulfill- Gender perspective - Gender-biased education - Equal opportunities.

\section{Introducción}

Es una verdad de perogrullo que el análisis de libros de texto es muy enriquecedor. Por su amplia cobertura, los mismos se convierten en "usinas de transmisión de contenidos ideacionales" como bien los describe Wainerman Rajman (1987:21), que además de incluir los contenidos normativos pautados por el Ministerio de Educación ofrecen recursos y medios para docentes. Y estos, junto con los maestros y profesores, son un soporte principal para influir el pensamiento, actitudes y el comportamiento del alumnado y moldearlos en serie independientemente de su bagaje cultural. Sin duda, la escuela como agente socializador transmite prácticas escolares arraigadas y asumidas como naturales en donde se determina y se establece un discurso hegemónico y pautas que el alumnado debe seguir para que todos sean educados igualitariamente y cumplan con las expectativas sociales deseadas. De esta manera, se regula la vida en 
sociedad, manteniendo estereotipos y relaciones de poder las cuales justifican actos discriminatorios, que comúnmente se perciben en los libros ya que el poder de transmisión de valores, creencias ideológicas que éstos poseen es ineludible.

Por tal motivo, este artículo se centra en la emisión del mensaje hallado en los textos e imágenes plasmados en la serie "Solutions" la cual fue publicada por primera vez en 2008 en Oxford University Press, departamento de la Universidad de Oxford. La misma consta de material educativo organizado por niveles (básico, intermedio, pre-intermedio y avanzado). En este caso particular, por una cuestión de claridad y brevedad sólo se analizaron cualitativamente los libros destinado a los primeros tres niveles: básico, intermedio y pre-intermedio para hallar temas recurrentes tales como las estructuras familiares presentadas, los roles de sus miembros, los campos semánticos asignados a mujeres y varones, así como también la asimetría de relación de mujeres y varones evidenciado por la posición que ocupa cada uno en la oración. Para ello, me pareció oportuno emplear la teoría del Análisis Crítico del Discurso (ACD) del lingüista holandés Teun Van Dijk la cual propone una relación entre cognición, sociedad, y discurso para hacer evidente y revelar que la elección de palabras y la sintaxis no es inocente ya que cada decisión está cargada de intenciones, valores, ideología; esta última vista como un conjunto de creencias y una forma de ocultamiento de intereses por parte de un grupo social que pretende validarlos universalmente mediante el dominio de sus ideas sobre un grupo determinado. Dicho poder es manifestado a través del discurso y reflejado por medio del uso de la manipulación, persuasión que controla 
e influye indirectamente el accionar de la gente y su mente. De hecho, se considera que toda elección de tema, método, teoría, es el poder que tiene el emisor del discurso una decisión política así como también aquellos editores y editoriales que eligen contemplar o no la cuestión de género en el material que lanzan al mercado.

\section{¿Qué se entiende cuándo se habla de Género y qué implica su perspectiva?}

De acuerdo a Marta Lamas (2000) esta categoría de análisis es un conjunto de creencias, experiencias, representaciones, y disposiciones sociales que se manifiestan entre los integrantes de un grupo humano en función de la diferencia anatómica que existe entre mujeres y varones. Por esta razón, el género está fuertemente arraigado a la cultura y a la sociedad. De este modo, estas construcciones estereotipadas producidas e impuestas por normas culturales, definen y naturalizan el comportamiento de varones y mujeres y con ello, la división sexual del trabajo, prácticas rituales y el ejercicio de poder; lo cual es tangible en los libros de texto de inglés. Consiguientemente, numerosas investigaciones, reflexiones y debates exponen que las diferencias entre las mujeres y los varones no son biológicas sino construcciones simbólicas pertenecientes al lenguaje y a las representaciones. De esta manera se puede afirmar que el género es el resultado de una performance cultural.

Asimismo, Joan Scott (1986) establece que el género es una construcción cultural, basada en ideas socialmente impuestas a los roles proporcionados para mujeres y varones, es decir, una categoría social impuesta sobre un cuerpo 
sexuado. Esta imposición cultural, observada tanto en las imágenes como en los textos de los libros de inglés analizados, se halla en la ubicación de los sexos en determinadas áreas semánticas que siguen un orden social natural patriarcal ${ }^{1}$.

\section{Las principales vertientes que se avizoran en la serie seleccionada}

A lo largo de estos años, los textos escolares fueron presentando algunas modificaciones planteadas también por el cambio de paradigma establecido en el sector pedagógico, la utilización práctica de la psicología para comprender los procesos cognitivos que los alumnos realizan, cambios económicos-sociales y el surgimiento de la perspectiva de género, razón por la cual, Silvia Grinberg (1998:4) indica que en virtud a distintos factores que se entrecruzan al momento del lanzamiento de un libro al mercado, el libro es "un producto multideterminado".

Particularmente, dentro de los libros de vanguardia que circulan hoy en el mercado para la enseñanza del idioma inglés, decidí analizar el libro "Solutions". Debido a la demanda previamente señalada, esta serie contiene tres libros (uno para el docente, dos para los alumnos - entre ellos uno para el trabajo en clase y el otro con actividades extras para reforzar lo dado en el aula- y un cd detrás del libro de clase que los alumnos pueden utilizar de forma independiente para

${ }^{1}$ Sistema de relaciones familiares, sociales y políticas fundado en el poder masculino sobre el trabajo, la sexualidad y las posesiones materiales de las mujeres. Requiere de la interdependencia y solidaridad de los varones, a pesar de las jerarquías internas que puedan existir en cada sociedad por clase, etnia y otros factores, las que se construyen y reproducen mediante la fuerza, símbolos, rotos, tradiciones, leyes, el sistema educativo, el inconsciente colectivo, la maternidad y heterosexualidad forzadas, la distorsión de la historia y la división sexual del trabajo.(Guzmán Stein, 2014: 12)

Revista Zona Franca- Centro de estudios interdisciplinario sobre las mujeres (CEIM)- Maestría poder y sociedad desde la problemática de género (MG), Rosario, Argentina. ISSN, 2545-6504 http://zonafranca.unr.edu.ar/index.php/ZonaFranca| Numero 26 (2018). 
ejercitar el aspecto de la lengua que ellos consideren necesitan afianzar, fomentando así la responsabilidad de los alumnos, la independencia y la autoeducación) para cada uno de los cinco niveles (básico, pre-intermedio, intermedio, intermedio superior y avanzado) para que los docentes puedan elegir de acuerdo a las necesidades de sus alumnos el material que resulte más apropiado para su curso.

Asimismo, los cambios ocurridos en más de cincuenta años en el campo de la psicología, en la educación con los distintos enfoques educativos en la enseñanza de una segunda lengua y en la tecnología no son un detalle menor, transformación que se refleja en los libros de texto analizados al observar consejos de corrección, explicaciones acerca de las posibles dificultades que un docente puede hallar a la hora de enseñar en un grupo que presenta distintos niveles de aprendizaje dado por el bagaje cultural y una guía sobre dislexia que explica a los docentes qué es, sus distintas formas, los síntomas, causas y cómo enseñar a la persona que la padece.

En cuanto al armado del material seleccionado, los autores, Falla, Tim y Davis, Paula explican en el prefacio de estos libros que los mismos son el resultado de un viaje de investigación con colegas de Oxford University Press en donde visitaron escuelas, observaron clases, y entrevistaron a docentes y alumnos, lo que les permitió detectar las necesidades de los mismos. Estos textos contienen diez unidades, las cuales tienen a su vez siete secciones. Estas secciones cubren las destrezas necesarias que los alumnos deberían poder 
desarrollar: la parte léxica, escrita, oral, auditiva, gramatical, lectora y socialcultural.

En este último aspecto, los autores incluyen textos y lecturas sobre deportes antiguos y contemporáneos .Además incorporan temas relativos al delito, avances tecnológicos, arte, educación, lugares de turismo, festivales musicales, comidas típicas, lenguaje corporal y costumbres en lugares exóticos y lejanos, Egipto, China, Japón y Australia.

En cuanto a las personalidades destacadas en estos textos aparecen representantes de la pintura, el deporte, literatura, política y cine, donde los varones son los más relevantes, entre ellos Pablo Picasso, Pelé, William Shakespeare, Alexander Graham Bell, Nelson Mandela, y sólo aparecen dos mujeres en este listado Marilyn Monroe en el cine y Marie Curie en la ciencia.

En relación a los campos semánticos se puede observar a simple vista, que la globalización permite trabajar con una gran variedad de temas desde el siglo XVIII hasta la actualidad. De igual modo, los alumnos tienen la posibilidad de conocer aspectos socio-históricos culturales de muchas partes del mundo, como Rusia, Finlandia, Japón. Adicionalmente a todas estas modificaciones en los libros de texto para la enseñanza del idioma inglés, Mariana Podetti (2011) señala concretamente que en la década de 1990 la representación tradicional de mujeres y varones en los textos escolares había desaparecido completamente, no obstante, a través de análisis llevado a cabo, se sigue detectando en los discursos 
una visión androcéntrica del mundo donde se margina a la mujer, descartando así cualquier posibilidad de igualar oportunidades para ambos sexos.

\section{Modificaciones sutiles, tendencias solidificadas}

Como expuesto recientemente, Podetti (Op. Cit) señala que a partir de la década del 80' han habido cambios en los libros de texto en cuanto a la representación de mujeres, varones y de la familia en su conjunto, las cuales son visibles en las fuentes analizadas. Si bien los libros incluyen alguna unidad dedicada a la familia, ésta institución no aparece como eje central; sino es ilustrada como una red de relaciones, en donde actores no pertenecientes a los lazos sanguíneos, como los amigos, también están incluidos, volcadas en árboles genealógicos, en imágenes de otras familias famosas, en algún comentario de sus protagonistas; es decir la visión de familia que se expone es distinta. La variante más significativa, aunque no la más representada, es la referencia de alguna familia monoparental y aquella compuesta por una pareja heterosexual sin hijos. Según Carmen Valdivia Sánchez (2008) y Georgina Binstock (2008) la postergación en el nacimiento del primer hijo, así como también una tendencia a familias reducidas son unas de las transformaciones más significativas de los modelos actuales.

Otra innovación es la ilustración de la familia a través de una adolescente; en libros de otras épocas se hubiese elegido a un varón como protagonista.

A pesar de las variables previamente señaladas en las representaciones de la estructura familiar, se observan algunas imágenes de familias ideales, ya sean 
famosas o no, como ser la familia Real Británica, Los Simpsons y donde a través de la descripción de sus miembros, se percibe en los roles familiares los patrones culturales del pasado. Estos roles estereotipados se refuerzan al ilustrar una familia con quince hijos en donde se describe la innumerable cantidad de quehaceres que la mujer debe realizar, contraponiéndose con la figura pasiva del esposo en el hogar, el cual queda exento de las actividades domésticas por su larga jornada de trabajo. Consecuentemente, no se puede notar una división de las tareas intra-domésticas porque la mujer hace todo. Del mismo modo, la descripción del texto va acompañado por la representación ideal de mujer, que condice con la apreciación de Wainerman (1997:6) quien resalta mujeres "inalterablemente" suaves, dulces y cariñosas que sólo se satisfacen cumpliendo su rol reproductivo.

Otra instancia ilustrada en los libros que refuerza los roles fuertemente estereotipados de los miembros de la familia así como también la división sexual del trabajo, es el caso de la familia de Bart Simpson. Mediante la descripción en torno a este personaje masculino, se establece la organización familiar en donde la madre se queda en el ámbito del hogar cuidando y atendiendo a todos en especial al bebé - "seres-para los-otros" según Lagarde (1996) y el padre, quien se desempeña como jefe de familia, trabajando en una planta nuclear los días de la semana y que durante los fines de semana solo mira la TV- "seres-para-si". Asimismo, se refuerzan los estereotipos de género socialmente permitidos para unos y otros, patrones que son enseñanzas diferenciales según un cuerpo 
anatómico o como dirá Scott (1986) sobre un cuerpo sexuado. Así, Lisa, como fiel reflejo de una niña, es inteligente y estudiosa, mientras que Bart, como cualquier representación varonil es vago para estudiar y no es socialmente condenado por esto, al contrario es "la estrella" y el protagonista del programa y de este apartado.

Otro ejemplo representativo en donde se detecta una clara intención de exponer una protagonista femenina muy conocida mundialmente es un texto dedicado a la Reina Isabel, pero una vez más los estereotipos son una tentación, ya que lo impactante no es el texto que acompaña la foto, sino la respuesta ante la pregunta que se halla arriba del texto: ¿Quién es Isabel? ( Falla, T. y Davis , P. 2012: 10) El libro brinda como respuesta: la madre de Carlos, y la esposa de Felipe. A pesar de la veracidad de las mismas, realmente, llama la atención que una mujer, que se destacó en el ámbito público, que es más reconocida que los varones de su propia familia tradicional, patriarcal y conservadora, se la describa por sus funciones materno-familiares y no se acentué su labor como jefa de estado. Teniendo como premisa la teoría de Van Dijk (Op. Cit.), es visible como a nivel pragmático, se enfatiza ciertos rasgos biológicos "naturales", construyendo así una imagen maternal de una jefa de estado. Como resalta Wainerman (1987:23), las mujeres en la historia son recordadas principalmente por el vínculo familiar (esposa, madre, hija) que ellas tienen con los varones quienes son los resaltados. Una posible y veraz respuesta a esa pregunta mencionada en el texto, que valoraría la superioridad que la Reina posee, podría haber sido: Isabel es la monarca № 54 o "la cabeza" de 620 organizaciones de beneficencia. 
A pesar de hallar elementos culturales tradicionales, con respecto a los roles, Palermo (2002) manifiesta que los mismos han ido cambiando debido a la escasez del ingreso familiar junto con la desocupación de jefes de hogares y como consecuencia la incorporación de las mujeres al empleo remunerado. Sin embargo, esta reforma social producto de una crisis económica, no está directamente plasmada en los libros de inglés de la actualidad, es como si los textos prefiriesen no involucrarse en esas cuestiones socio-políticas. Se detecta como explica Wainerman (2003) hogares con dos proveedores en donde se advierte la inclusión de las mujeres y de los varones en el ámbito doméstico en un intento de democratización de las tareas del hogar, pero se desconoce la razón por la que ambos progenitores trabajan.

Por ello, es trascendente destacar que se perciben muchas más mujeres inmersas en el mundo público ejerciendo una gama más variada de profesiones donde se las ve ocupando cargos de conducción, planeamiento y dirección, dirá Wainerman (1997:21) con más protagonismo, y no sólo aquellas que son una extensión del rol natural maternal de cuidado, motivo por el cual, los hijos y/o el esposo suelen estar comprometidos en hacer determinadas tareas domésticas por no encontrarse la madre en la casa, ya que ésta trabaja la misma cantidad de horas o más que el padre.

Consecuentemente, se perciben protagonistas adolescentes que cuidan de algún hermano/a menor, hacen mandados, ponen la mesa y cocinan. La contribución familiar, es vista como una mera ayuda porque en definitiva todas las 
responsabilidades domésticas son pura y exclusivamente de la mujer de la casa. Si bien se advierten modificaciones, éstas son mínimas ya que no se exime a la mujer de ser la encargada de organizar el hogar con todo lo que eso incluye, además de ejercer su profesión, cumplimentando así como indica Koldorf (2008) una doble, y cuando no una triple, jornada laboral, es decir los cambios no son satisfactorios en cuanto la desigualdad entre los sexos y aún no se ha logrado plasmar en el material de estudio una democratización genuina de las tareas del hogar.

\section{Nuevos destinos aunque limitados horizontes}

En esta sección se expone en que área semántica se ubican a mujeres y varones en los textos de esta década. De acuerdo a la teoría del Análisis Crítico del Discurso, el campo semántico es interesante porque se puede detectar la localización de un sexo u otro en un determinado espacio debido a su anatomía y cómo la relevancia social que tenga dicho espacio, le da cierta autoridad, poder o jerarquía a la persona que se encuentra expuesta en ese ámbito.

Tal como se ha detallado anteriormente, la feminización laboral mencionada por Wainerman (1997:17) junto con los cambios sociales, económicos trajeron alteraciones en las estructuras familiares, en la distribución de las tareas así como también en los espacios donde se hallan a mujeres y varones. Estas modificaciones sociales otorgaron ciertos permisos para ambos y estos cambios se ven reflejados en el material analizado donde los varones experimentan el roce en el mundo de la moda, la danza clásica, y en donde las mujeres pueden hallarse 
en el mundo del cine, deporte, arte, música, literatura, e incluso, se las puede encontrar profundamente inmersas en el mundo laboral realizando tareas "masculinas" por excelencia como es la albañilería, obteniendo así la posibilidad de manejar su propio dinero y decidir sobre él, lo que le garantiza también, según Wainerman (1997:15), alcanzaruna autonomía e independencia del marido y al mismo tiempo una doble jornada laboral; dentro y fuera de casa, como se mencionaba anteriormente. La variedad de ámbitos donde se puede localizar a las mujeres, es directamente proporcional a los roles que ellas cumplen hoy en día.

Otra novedad de la época que también subraya Graciela Morgade (2012) en algunas editoriales de los textos de vanguardia, es la presencia de otras razas como ser alguna mujer o varón de raza negra.

No obstante, sigue habiendo ciertos ámbitos en dónde los dos sexos no aparecen, o no están equiparados, tal es el caso de la relación profesional paciente, en donde la mayoría de las veces, la mujer es la que espera pasivamente y se entrega a las instrucciones de un médico varón quien ocupa el rol de autoridad y superioridad que le otorga sus conocimientos y sabiduría. La misma preferencia masculina está presente en un artículo donde se aborda el tema de los héroes y aparecen sólo ejemplos de varones como ser Martin Luther King, Nelson Mandela y Mahatma Gandhi, eximiendo a las mujeres de la posibilidad de encontrarse en la esfera pública y de la posibilidad de que alguien se pueda identificar con ellas. 
Al respecto Van Dijk dice que toda elección tiene un motivo, una razón. La elección de los autores del libro de no incluir a alguna líder femenina, implica, a nivel pragmático, que la cognición social no las encuentra ejerciendo un rol de liderazgo por carecer iniciativa que se necesita para desempeñarse y destacarse en la política, la religión, motivo por el cual se deduce que las mujeres sólo figuran como modelo a seguir en ámbitos sin trascendencia y esto se ve aparentemente justificado con la aparición de un artículo sobre la vida de Paris Hilton, ubicado unas páginas más adelante en relación al artículo anterior. Este artículo se lo interpreta como una antítesis de los valores, actitudes, pensamientos de Nelson Mandela, Mahatma Gandhi y Neil Armstrong, destacados anteriormente en el libro "Solutions" Elementary, ya que si se considera la teoría del Análisis Crítico del Discurso, el autor mediante la sintaxis utilizada subraya una falta de esfuerzo y responsabilidad por parte de la modelo a la que todo se le hace posible sólo por tener una familia adinerada y no por intelecto o empeño personal. Si bien esta innovación de incluir a una mujer como protagonista es valorable y favorable para la emancipación de la mujer, se podría deducir mediante el uso de la pragmática que lejos de lograrlo, la ubica en el lugar estereotipado de belleza, moda que ocupa en la mayoría de los libros. De esta manera, la imagen de la mujer termina siendo devaluada como un simple patrón de belleza, agradable para agradar en donde se deduce que los ejemplos anteriores referido a los varones, son sobrevaluados como predicadores del ideal de buen ciudadano, categoría social destinada únicamente para ellos para lo cual son educados, desde la época de Jean Jacques Rousseau como indica Rosa Cobo (1995), con el fin de desempeñar 
las funciones sociales necesarias para la reproducción de la sociedad patriarcal.

Se legitima así una mirada del mundo estereotipada con una justicia social que como explica Sánchez Bello (2002) revaloriza los modelos masculinos e infravalora los femeninos.

\section{Asimetría de relación en mujeres y varones}

El empleo de la teoría del "Análisis Crítico del Discurso" ha ayudado a detectar las jerarquías sutilmente establecidas en las fuentes analizadas, dada por la utilización de recursos estilísticos que logran ubicar al varón en un determinado lugar preferencial de la oración, el cual le otorga mayor control lingüístico. Además, el área donde se ubican a mujeres y varones, tampoco es inocente, ya que por medio de su ubicación, se transmiten pautas de género, estereotipos y concepciones que crean prejuicios sexistas.

Estas inequidades entre el varón y la mujer se mantiene en el discurso y en las imágenes analizadas donde se detecta la voz exhibida y la voz silenciada, debido a los obstáculos y lejanía que subliminalmente se les presenta a las mujeres a pesar del ofrecimiento de una gran variedad de lugares antes vedados por ellas.

\section{Algunas consideraciones}

Los libros de textos son instrumentos de imposición cultural que la escuela utiliza, entre otras cosas, para portar un mandato social. Consecuentemente, la importancia que cobra el libro escolar como herramienta pedagógica recae en su 
irrefrenable transmisión de actitudes, valores, y conductas que estos mismos refuerzan y/o anulan a través de sus contenidos e imágenes y en el efecto que estos ocasionan en la población estudiantil que lo recepcionan y asimilan como discursos legítimos engarzados en la institución escolar, espacio signado, en el decurso de los siglos, por la autoridad. Consecuentemente, el contenido plasmado en estos materiales de estudio, al formar parte de un discurso dominante, distan mucho de ser neutros.

\section{El advenimiento de nuevas constelaciones familiares}

De acuerdo a lo hallado en los materiales de estudio, se observa que ha habido un cambio de punto de vista, ya que no se expone la familia de un personaje a lo largo del material de estudio sino que junto a los ejemplos de familia de gente común, se incluyen las familias de celebridades, difundiendo así una visión más globalizada, desdibujada y menos personalizada de ésta institución. Si bien, la misma se ha ido transformando a raíz de diversos factores económicos-sociales y culturales, dando lugar a otros tipos de modelos familiares, la nuclearización de esta institución es la más distinguida.

Con respecto a los roles desarrollados por sus miembros, los libros de la actualidad tienden a ejemplificar solapadamente en su discurso, la distribución de tareas sesgada tradicional. No obstante, se incluye la colaboración de los integrantes en las obligaciones domésticas. Una justificación plausible de esta modificación se debe, entre otros factores, a la presencia de familias de doble proveedores. Asimismo, la creciente difusión de esta contribución moderna es sólo 
eso, una ayuda, ya que los quehaceres del hogar y del cuidado siguen siendo tareas indiscutidamente privativas de las mujeres, reproduciendo así los estereotipos de género tradicionales.

\section{El género como elemento constitutivo que determina un espacio social}

Hoy en día, mujeres y varones no se ven tan compelidos a seguir los estrictos patrones sociales según su sexo, contribuyendo así funcionamiento esperado de la sociedad. Se divisan en las fuentes seleccionadas, descripciones que tratan de salirse de ese molde conservador, incluso se intenta exponer mujeres y varones de otras razas y culturas, aunque se advierte una pequeña inclusión de sujetos de raza negra, orientales y estereotipos culturales al haber escasas referencias de costumbres y modos de vida latinoamericana.

En cuanto a la esfera pública, se implementa la posibilidad del cambio de profesiones entre mujeres y varones y de preferencias no esperadas socialmente conferidas a su sexo, tratando de desafiar a los estereotipos; tales son los ejemplos de una mujer mecánica y un varón partero, o chef. Precisamente, las mujeres de la actualidad han conquistado otras esferas de la sociedad y junto a ello, su presencia en otros lugares, aumentando así sus roles. Este aspecto también se percibe en los libros para la enseñanza del idioma inglés, en donde se resalta una variada cantidad de las actividades que ellas realizan. De igual modo, se aprecia la idea del disfrute y el placer, por lo que la imagen de la mujer no es la de la abnegada y sacrificada de antes. Quizás la razón estriba en el creciente entronizamiento de la valorización de la realización personal y un nuevo concepto 
del trabajo como un espacio donde se cultivan amistades y un lugar que le es propio para ella.

En cuanto a los varones, se tiende a hallarlos realizando tareas domésticas y volcados a actividades tradicionalmente femeninas como el ballet, intentando de esta manera achicar la desigualdad entre mujeres y varones presentándolos a ambos en espacios aparentemente iguales. A pesar de ello, esta disminución de la inequidad es pequeña debido a que la incursión masculina en el hogar, reviste de una característica opcional y no concerniente a la crianza de los hijos, así como también la presencia femenina en cargos jerárquicos aún es desdeñable, reforzando así una ideología social patriarcal muy arraigada que no está dispuesta cambiar por completo tradiciones culturales arbitrarias existentes y materializando así el "techo de cristal" que las mujeres intentan traspasar.

\section{¿Cambio estructural o aparente?}

De acuerdo a lo investigado, es muy auspicioso encontrar en los libros de vanguardia una diferenciación en cuanto al orden establecido en muchas ocasiones se elige empezar una enumeración con un pronombre o sustantivo propio femenino. Pero, al hurgar y analizar los discursos, se percibe el modelo de mujeres orquestas y varones sólo relacionados a lo doméstico en casos excepcionales como una mera ayuda. Por esta razón, se deduce que las mujeres se destacan por haber hecho un cambio más significativo que los varones. Del mismo modo, se visualiza una jerarquía en donde el varón al estar asociado a la 
ciencia, tecnología y a la producción, en un mundo propiamente laboral, se considera superior; por lo que dicho intento termina siendo insignificante.

Esta desigualdad desprestigia a las mujeres al no mencionarlas en ámbitos de liderazgo, al ubicarlas como un mero objeto de belleza y moda, al describirlas como seres dependientes de alguien en especial de algún varón - "madres de, esposas de". Los estereotipos y prejuicios encontrados no hacen más que afirmar la reproducción del status quo. A partir de esta constatación, se sostiene y se afirma que a pesar de los aires de cambio observados en los libros de texto, la intención de impedir estas diferencias entre mujeres y varones es vaga y sutil por lo que la asimetría entre ellos aún persiste y los estereotipos de género hallados siguen estando fuertemente enraizados a una postura androcéntrica, dando como resultado instancias sexistas en las fuentes estudiadas.

En cuanto a las temáticas presentadas en la actualidad en los libros de inglés, éstas tienden a ser variadas, globalizadas y atractivas. Se discuten distintas cuestiones como la importancia de la ciencia, costumbres culturales de oriente y occidente, festivales típicos, desastres mundiales como la hambruna, la guerra. Pero, se advierte una ausencia destacada en cuanto el abordaje de temas sensibles, como ser aquellos relacionados a la política, la religión. De acuerdo a Van Dijk (Op. Cit) toda inclusión u omisión de alguna palabra o tema en el discurso es una decisión política; el hecho de elegir no hablar de femicidio, la trata de personas y la violencia de género cuando se enumeran problemáticas mundiales como la droga, guerras y demás, marca una postura por parte de los autores de 
pretender ser imparciales o simplemente hacer caso omiso a lo que está sucediendo mundialmente.

\section{Apreciaciones finales, aunque no absolutas}

A la luz de lo expuesto, y considerando la teoría de Análisis Crítico del Discurso de Van Dijk (Op. Cit.), si bien se avizora en los libros de texto un leve aumento de las mujeres representadas en el ámbito público, y una intención por pretender equiparar los derechos y espacios de ambos sexos, ineludiblemente, esta inclusión no es suficiente. A pesar del uso de las nuevas tecnologías y avances en la investigación en cuestiones de género quienes han garantizado una evolución hacia la visibilización de dicha desigualdad, actualmente, los libros sustentan una aparente equidad pero en el fondo siguen transmitiendo instancias de exclusión.

Según el ACD, quien controla el discurso público, controla ampliamente la mentalidad social, e indirectamente la acción pública. Por eso se cree que al analizar los libros de texto de inglés con perspectiva de género, indiscutidamente, ayuda a los docentes a influir en un proceso social, cultural en donde los alumnos como las editoriales estén atentos a incluir esta problemática; para que la escuela logre verdaderamente educar equitativamente a mujeres y varones para finalmente satisfacer la acuciante necesidad de brindar la tan esperada igualdad de oportunidades y participación. Se coincide con Stroppa (2000) que la introducción de la perspectiva de género en la educación les ofrece a los alumnos una visión más global de la humanidad, contribución en la enseñanza que fomenta 
el desarrollo de los alumnos como personas en sus funciones sociales y evita la discriminación.

Con motivo de promover el respeto por los demás, la reflexión, y un presente plural se concuerda con Laura Menéndez (1999) que es "imprescindible asumir el compromiso que implica tomar un conjunto de decisiones didácticas $y$ metodológicas, las cuales sólo pueden ser concebidas habiendo asumido una postura clara frente a las cuestiones de género a la finalidad de la historia dentro de la escuela y su relación con la construcción de una identidad personal y social y una memoria colectiva". Seguramente la pregunta que concita mayor interés será cómo lograrlo.

\section{Propuestas viables}

En primer lugar como docentes deberíamos promover un currículum no sexista incluyendo pequeños aunque esenciales cambios. Acuerdo con Podetti (2011) que para despejar instancias sexistas en los libros escolares, sería oportuno eliminar generalizaciones basadas en el sexo, presentar a las mujeres como sujetos activas en el progreso de la sociedad, promover la igualdad de presencia y protagonismo entre mujeres y varones, presentar activamente a ambos sexos en los quehaceres domésticos al igual que en las actividades profesionales, incluir la explicación de los motivos que provocaron una discriminación hacia las mujeres en la historia y finalmente, incorporar perseverantemente la Educación Sexual Integral en nuestras aulas aunque en la provincia de Santa fe sólo sea un programa. En suma, para alcanzar una igualdad 
entre ambos sexos, es fundamental desarrollar políticas de empoderamiento que acrecienten las potencialidades de cada uno y no el dominio del otro, para aumentar así las libertades individuales.

Conforme a lo desarrollado hasta aquí, reitero las palabras de M. Antonia Gallart (1993) "la metodología cualitativa es una de las posibles lecturas y como tal no puede ser absolutizada", razón por la cual, lo analizado en estos materiales de estudio puede lógicamente cambiar en el futuro, e incluso estimo que pueda favorecer la apertura de nuevos aportes teóricos, que es de alguna manera lo que se pretende a partir de esta publicación.

\section{Bibliografía}

BINSTOCK, Georgina (2008). "Cambios en la formación de la familia en Argentina: ¿cuestión de tiempo o cuestión de forma?" III Congreso de la Asociación Latinoamericana de Población, ALAP, realizado en Córdoba Argentina, del 24 al 26 de Septiembre de 2008. [Citado mayo de 2015]. Disponible en

Internet

en:

<http://alapop.org/2009/images/DOCSFINAIS PDF/ALAP 2008 FINAL 181.pdf>

BURíN, Mabel (1994). "Psicoanálisis y Género en la Actualidad". Periódico de Divulgación Psicológica.

CARLÓS, Luis (2010). "En Torno al Análisis de Textos Escolares". [Citado mayo de 2016]. Disponible en Internet en:

$\leq$ www.fhumyar.unr.edu.ar/escuelas/3/materiales\%20de\%20catedras/trabajo\%20d e\%20campo/textos.htm>

COBO BEDIA, Rosa (1995). "Fundamentos del Patriarcado Moderno. Jean Jacques Rousseau". España, Madrid: Ediciones Cátedra. Universitat de Valencia. Instituto de la Mujer. 
GALLART, M. Antonia (1993). "Métodos Cualitativos II. La práctica de la Investigación". La Integración de Métodos y la Metodología Cualitativa. Una Reflexión desde la Práctica de la Investigación. Buenos Aires: Centro Editor de América Latina.

GRINBERG, Silvia y PALERMO, Itatí (2000). "Mujeres y Trabajo en los Textos Escolares: Crisis y Perspectivas". Educere, Perspectiva de Género. Vol 11. Art 4. Oct, Nov, Dic. [Citado enero de 2009].Disponible en Internet en: $<$ www.saber.ula.ve/db/ssaber/Edocs/pubelectronicas/educere/vol4num11/articulo4 -11-12.pdf> (1998). "Texto Escolar y Mercado Editorial en Contextos de Transformación Educativa“. Propuesta educativa Nro. 17 (FLACSO) [Citado junio de 2016].Disponible en Internet en: $<$ uww.academia.edu/710426/Texto y contexto de los libros escolares>

GUZMÁN STEIN, Laura (2014). "Relaciones de Género y Estructuras Familiares: Reflexiones a Propósito del Año Internacional de la Familia". [Citado marzo de 2015].Disponible en Internet en: $<$ http://www.ts.ucr.ac.cr/binarios/docente/pd-000114.pdf>

KOLDORF, Ana Esther (2008). "Familia y Nueva Pobreza desde una Perspectiva de Género. (Rosario, 1994-2002)". Rosario: Ediciones Prohistoria.

LAGARDE, Marcela (1996). "El género", fragmento literal: 'La perspectiva de género', en Género y feminismo. Desarrollo humano y democracia, España: Ed. horas y HORAS, 13-38 pp.

LAMAS, Marta (2000). "Diferencias de Sexo, Género y Diferencia Sexual". Cuicuilco, enero - abril año/vol., número 018. Escuela Nacional de Antropología e Historia (ENAH). Distrito Federal, México.

LEFFINGWELL, William (1992). "Integrating Gender Studies Materials into the Basic Currículum". Hacia un Currículo no Sexista. Integración de los Estudios de la Mujer y el Género en los Cursos Introductorios de Español, Inglés y Ciencias sociales en la Universidad de Puerto Rico. Cayey. 
MENÉNDEZ, Laura (1999). "Historia, Género y Mujeres en la Educación General Básica".VII Jornadas Interescuelas. Departamento de Historia. Universidad Nacional de Comahue.

MORGADE, Graciela (2012). "Aprender a ser mujer, aprender a ser varón”. Argentina: Noveduc.

PALERMO, Itatí (2002). "Familias Argentinas al Iniciarse el 3er Milenio". Universidad Nacional de Luján. Argentina. [Citado abril de 2015].Disponible en Internet

en:

<blog.cps.org.ar/sites/default/.../Familias Argentinas Tercer milenio.doc $>$

PODETTI, Mariana (2011). "Mamá ya no Amasa. Género y Edición en los libros de texto". En Revista Mora. Cuidad Autónoma de Buenos Aires. Sept. Vol. 17. $N^{\circ}$ 2. [Citado Junio de 2016]. Disponible en Internet en: $<$ http://www.oalib.com/paper/2504728\#.V18HNdLhDIUI> ISSN 1853-001X.

SÁNCHEZ BELLO, Ana (2002). "El Androcentrismo científico: El obstáculo para la igualdad de Género en la escuela actual”. Educar (en línea)., № 29. Pp 91 102. [Citado mayo de 2016]. Disponible en Internet en: <https://dialnet.unirioja.es/ejemplar/56650>

SCOTT, Joan (1986). "El género: una categoría útil para el análisis histórico". En Lamas, Marta. (Comp.) El Género: La construcción cultural de la diferencia sexual. México: PUEG, pp. 265-302

STROPPA, Maricel (2000). "El Género: Algo más que una Categoría Gramatical". Propuestas de la Problemática del Aula a las Propuestas Concretas. CELA: Centro de Linguística Aplicada. Rosario: Publicación Facultad de Humanidades y Artes. Universidad Nacional de Rosario. 75-88 pp.

VALDIVIA SÁNCHEZ, Carmen (2008). "La Familia: Concepto, Cambios y Nuevos Modelos". La Revue du REDIF. Vol 1. 15-22 pp. [Citado marzo de 2015]. Disponible en Internet en: http://spereira.cl//magenes/familia.pdf

VAN DIJK, Teun (1999). "El Análisis Crítico del Discurso" en Anthropos (Barcelona), 186, Sept-Oct 23-36 pp. Trad. González de Ávila, Manuel. [Citado julio de 2015]. Disponible en Internet en: 
<http://www.discursos.org/oldarticles/El\%20an\%E1lisis\%20cr\%EDtico\%20del\%20 discurso.pdf>.

WAINERMAN, Catalina (1997). "Nuevas mujeres, Nuevas familias". En: Argentina en el Tercer Milenio. Buenos Aires. Atlántida. 247-270 pp. [Citado julio de 2016] Disponible en Internet en: $<$ http://www.catalinawainerman.com.ar/pdf/Nuevas-mujeres-nuevas-familias.pdf>. (2005) "La Vida Cotidiana en las Nuevas Familias. ¿Una revolución estancada?’. Buenos Aires: Ediciones Lumiere.

(1987) y RAIJMAN, Rebecca. "Sexismo en los Libros de Lectura de la Escuela Primaria". Buenos Aires: Ediciones del IDES. y otros (1983). "Del Deber Ser y Hacer de Las Mujeres. Dos Estudios de Caso en Argentina." El Colegio de Méjico / PISPAL. Méjico.

\section{Fuentes.}

FALLA, Tim y DAVIS, Paula (2012). Solutions Elementary. Great Britain. Oxford University Press.

Solutions Pre-intermediate. Great Britain.

Oxford University Press, 2012. Solutions Intermediate. Great Britain. Oxford

University Press, 2012.

Revista Zona Franca- Centro de estudios interdisciplinario sobre las mujeres (CEIM)- Maestría poder y sociedad desde la problemática de género (MG), Rosario, Argentina. ISSN, 2545-6504 http://zonafranca.unr.edu.ar/index.php/ZonaFrancal Numero 26 (2018). 